\title{
Is Deteriorating Air Quality Impacting Stock Performance in India? Air Quality Index Predicts Stock Performance
}

\author{
Divya A Reddy ${ }^{1, *}$, Dr. Siddharth Misra ${ }^{2}$, Sindhu P.J. ${ }^{1}$, Shijin Premarajan ${ }^{1}$ \\ and Shijo John ${ }^{1}$ \\ ${ }^{1}$ Krupanidhi Group of Institutions, Bangalore, India \\ ${ }^{2}$ Accendere Knowledge Management Services, CL Educate Ltd., Bangalore, India
}

\section{Article Type: Article}

Article Citation: Divya A Reddy, Siddharth Misra, Sindhu PJ, Shijin Premarajan, Shijo John. Is deteriorating air quality impacting stock performance in India? Air quality index predicts stock performance. Indian Journal of Science and Technology. 2020; 13(02), 103-113. D0l: 10.17485/ijst/2020/ v013i02/ 149389

Received date: December 3, 2019

Accepted date: December 27, 2019

*Author for correspondence: Divya A Reddy divyanikhil0205@ gmail.com 9 Krupanidhi Group of Institutions, Bangalore, India

\begin{abstract}
Background/objectives: This study attempts to examine a systematic relationship between air quality index (AQI) and the performance of stock markets in India. India has ranked among the bottom five countries in environmental performance index (EPI) by World Economic Forum (WEF). Previous studies in this field conducted in other parts of the world indicate a direct relation between environmental performance and market performance; however, the case of India may prove to be different considering the Indian environmental policy, environmental accountability, population, and income and development aspects. Methods: We have employed linear regression technique to ascertain the impact of AQI on stock returns. AQI data from 13 stations across India are the dependent variables. These dependent variables are each regressed individually for each stock market index from Bombay Stock Exchange (BSE) equity index, Sensex. Therefore, there are 17 models where $A Q$ I from the chosen 13 stations has been regressed with each of the industry specific index. A descriptive analysis is also performed to know the yearly averages of the AQI across stations used in the study. Findings: Our results confirm that there exists a negative association between $A Q I$ and stock returns for top-performing growth stocks. The results also indicate that there is a positive association between AQI and capital intensive industry stocks, while a negative association was observed in the case of labor-intensive industries. The findings indicate that AQI is a predictor for stock returns in India in the short term. Application: Environmental influences on stock market performance are becoming more potent than ever before as the negative externalities of pollution impact the financial performance of corporations.
\end{abstract}

Keywords: Air Quality Index, Stock Performance, Environmental Policy, Indian Stock Market, Air Pollution. 


\section{Introduction}

India is consistently dominating the list of world's most polluted cities in the world from past few decades. The latest report by the world economic forum states that 7 of world top 10 polluting cities and 22 of 30 world's worst polluting cities are from India. Air pollution is an important factor influencing public health, economy, and policy. Mature financial markets tend to respond to such stimuli which affect the nation in many dimensions. Air pollution, which itself is a negative externality of economic growth, becomes a strong predictor for financial market performance [1].

Studies have attempted to understand the relationship between air pollution and stock performance from various perspectives. Most popular perspective is where studies have established that environmental stimuli can significantly affect the performance of stocks as they affect the investor mood and sentiments [1-3]. Another perspective is where pollution information and environmental awareness play important role in stock performance [4]. A few studies associate reactions to environmental regulation and company's environment protection efforts as an indicator of stock performance [5-7].

Significant amount of research in this area has been conducted in China in recent years which have asserted that there is a negative association between air quality and stock performance [8-10]. India is facing similar challenges that China faced a few decades ago. India is the second most populated nation in the world after China; and like China, India too is battling high levels of air pollution due to increasing industrialization and urbanization. The unique contribution of this study is that it is one of the few studies that attempts to establish an association between air quality index (AQI) in India and the stock performance of listed companies in Bombay Stock Exchange (BSE). The study furthers the understanding by breaking the stock performance down industry-wise as a reaction to changes in air quality.

\section{Literature Survey}

In this section, we discuss the various perspectives provided by previous studies linking Air quality and stock performance, and provide rationale for choosing India to test if an association exists between air quality and stock performance in India.

Numerous studies have established that external physical environment can influence the performance of stocks. Research in behavioral finance takes a lead in explaining this phenomenon. Studies have associated the impact of weather on investor mood, thus impacting the trading of stocks in various stock exchanges around the world. One of the earliest works on this was the impact of weather on NYSE market indices were studied. Many studies have further explored on this aspect and found that adverse weather conditions negatively impact the trading in stocks [11]. Seasonal affective disorder (SAD) is listed as one of the possible reasons affecting the mood of the investors which, in turn, affect the prices and thus the returns on stocks.

In [12], explore the air pollution influences on negative mood effects of investors and stock returns in United States. Air pollution affects physical and psychological well-being 
of investors. Some immediate reactions to rise in pollution can be breathing difficulties, irritation, nausea, anxiety, depression, anger, and stress to name a few. These reactions can have a significant impact on the mood and decision-making of investors. It was found that AQI is negatively associated with stock returns, and this relation was stronger when the trader was investing more polluted areas. Taking off from the findings of this study, many studies have emerged from China which is fighting extreme effects of pollution like haze pollution and high levels of PM 2.5 in its cities [13-14]. These studies in China have found that trading volumes were affecting by air quality in short term, thus providing the link between investor mood and stock performance. High levels of pollution resulted in low returns, higher volatility, and high illiquidity in Chinese stocks. These effects were more evident in growth stocks, volatile stocks, and distressed stocks.

Public environmental awareness and pollution information are used as links to understand the association between pollution and stock returns in few studies. It was noted that pollution performance news of individual firms affected the stock prices of the respective firms. Shareholders experienced negative returns when media reported increase in emissions, waste, and pollutants by the firms that public environmental awareness attributed to the intensity of the negative returns as reaction to an increase in air pollution. Findings of these studies not only attribute the changes in stock returns due to investor mood but also provide the rationale to investor behavior which is influenced by market information about air pollution along with actual changes in external physical environment.

Investor reaction to new market information on environmental policy and company's environmental performance on stock performance is another aspect that provides an important dimension to the air quality-stock performance effect. It was observed by few studies that in the long run, companies that are environmentally responsible have better stock performance [15-17]. Bad environmental performance leads to reduction in market value, thus affecting investor's decisions, while adherence to environmental regulations is rewarding which is reflected in profitability, market value, and stock performance of the firms.

In [18] light of the findings of the above studies, one may reflect on the fact that is the relationship between AQI and stock performance purely a behavioral phenomenon? If adherence to environmental regulations is financially rewarding, then why are stocks getting affected by poor air quality? Are there no economic justifications for this phenomenon? The findings of the present study can help provide an understanding to these questions by studying the Indian market stock performance with respect to deteriorating AQI. Indian ambient air quality is worsening consistently since past 25 years. Currently, the average PM2.5 concentration in the country is $74.3 \mu \mathrm{g} / \mathrm{m}^{3}$ which is a way above the prescribed limits by the World Health Organization. Over $90 \%$ of India's population is exposed PM 2.5 levels more than $35 \mu \mathrm{g} / \mathrm{m}^{3}$, which puts the people at severe risk for lung diseases, cancer, heart disease, and respiratory disorders to name a few. Over 1.1 million deaths in India in 2015 were attributed to exposure of particulate matter (PM) air pollution (GBD MAPS Working Group. 2018). Given the current situation of India with respect to air quality, it becomes imperative to understand if this is impacting stock performance in Indian stock markets. 


\section{Data}

The AQI data for the period on 1 year from 1 November 2017 to 31 October 2018 were sourced from Central Pollution Control Board, Ministry of Environment, Forest and Climate Change, Government of India, online data base. AQI is the 24-hourly average concentration of at least 3 of 8 pollutants monitored which includes PM 2.5, PM 10, $\mathrm{CO}, \mathrm{O}_{3}$, and others. The AQI data from a total of 134 stations through the country were obtained. However, due to missing data for several dates of many stations, finally AQI from 13 stations from across the country was chosen for the study. Moving average method was used to fill in the missing data for the chosen 13 stations. The stock performance in the study is measured by the BSE equity index, Sensex data. The data have been sourced from the BSE India online data base archives. The closing value of total of 17 indices for the period of 1 year from 1 November 2017 to 31 October 2018 was used in the study. To gain a better understanding, the air quality impacts stocks from across industries differently, we have used industry specific BSE indices such as BSE Energy, BSE Auto, and so on. The details of the stations chosen for AQI and BSE indices are stated in the annexure.

\section{Methods}

We have employed linear regression technique to ascertain the impact of AQI on stock returns. AQI data from 13 stations across India are the dependent variables. These dependent variables are each regressed individually for each stock market index from BSE equity index, Sensex. Therefore, there are 17 models where AQI from the chosen 13 stations has been regressed with each of the industry specific index. A descriptive analysis is also performed to know the yearly averages of the AQI across stations used in the study. Since AQI data for few dates were missing for the stations, the moving averages method was used to fill in the missing data. Normality of the data for all variables was checked by constructing normality plots before performing the linear regression analysis. Initially, linear regression was performed only for BSE 50 and BSE 500 to understand the impact of AQI on best-performing stocks at the national level irrespective of the industry specification. Later regression was performed on 15 industry-level BSE indices to further understand if variations of the effect exist across different industries.

\section{Results}

In this section, we empirically verify if AQI impacts stock indices [19]. First, it is worth noting that the average AQI of all chosen stations exceeded the prescribed limit by WHO, i.e., $35 \mu \mathrm{g} / \mathrm{m}^{3}$. All stations' average is at least double the WHO prescribed limit of the healthy range. Some stations' yearly average is toxic exceeding $100 \mu \mathrm{g} / \mathrm{m}^{3}$. Such toxic levels of AQI adversely affect physical and psychological well-being of the population and thus can be deemed to impact the well-being and moods of the investors. This helps in interpreting the regression results discussed later uniformly without bias. Table 1 displays the Mean AQI for the 13 stations chosen. 
TABLE 1. Display of yearly average AQI

\begin{tabular}{lc}
\hline \multicolumn{2}{c}{ Descriptive statistics } \\
\hline Station name & Mean of AQI \\
\hline Bhopal Chauraha, Dewas - MPPCB & 90.259876 \\
Chandrapur, Chandrapur - MPCB & 88.139260 \\
Gangapur Road, Nashik - MPCB & 89.544523 \\
Karve Road Pune, Pune - MPCB & 74.841156 \\
RIMT University, MandiGobindgarh - PPCB & 110.569152 \\
Adarsh Nagar, Jaipur - RSPCB & 143.340193 \\
Manali, Chennai - CPCB & 91.779486 \\
Velachery Res. Area, Chennai - CPCB & 66.002856 \\
Bollaram Industrial Area, Hyderabad - TSPCB & 77.017121 \\
ICRISAT Patancheru, Hyderabad - TSPCB & 76.864583 \\
IDA Pashamylaram, Hyderabad - TSPCB & 86.060832 \\
Central School, Lucknow - CPCB & 157.761733 \\
Lalbagh, Lucknow - CPCB & 192.478558 \\
\hline
\end{tabular}

Source: Author's compilation

Further, when linear regression was performed BSE 50 as the dependent variable and AQI of the 13 stations as independent variables, results clearly established that there exists a negative relation between AQI and stock returns. Table 2 displays the beta coefficients of the results. Statistically significant results were observed in three stations confirming this negative association. BSE 50 is index that comprises of top 50 performing companies listed in the BSE based on their market capitalization, stock price, and number of share for a base period. Therefore, we can assume that AQI has a significant impact on the performance of top growth stock of Indian stock market. Similar results were observed for BSE500. There is a negative association observed between AQI and Stock indices for BSE top 500 companies. However, one station produced a statistically significant result for a positive association between the two variables similar to the findings of many previous studies.

We strongly felt the need to break these results down further and verify if the results might vary when industry specific indices were considered. Table 3 displays the beta coefficients of the regression results performed using industry specific indices as dependent variables. Interesting results were observed as not all industries confirmed this negative impact of AQI on stock returns. A considerable number of industries produced statistically significant results confirming a positive association between the two.

A negative association between AQI and stock performance was observed in banking industry, finance, health care, information technology, fast-moving consumer goods (FMCG), and energy sectors, while banking, finance, health care, and IT are relatively nonpolluting industries and labor intensive. Mitigating the externalities of poor air quality can result in higher costs and overheads for the companies, thus affecting profitability in turn affecting the stock performance. FMCG and energy sector are highly polluting industries and capital intensive. Due to environmental regulations and negative externalities of poor air quality compel the companies to employ measures to reduce emissions, thus increasing the cost of production affecting the profitability of the firms [20]. It must be highlighted that strongest association was observed with respect to information technology industry. 


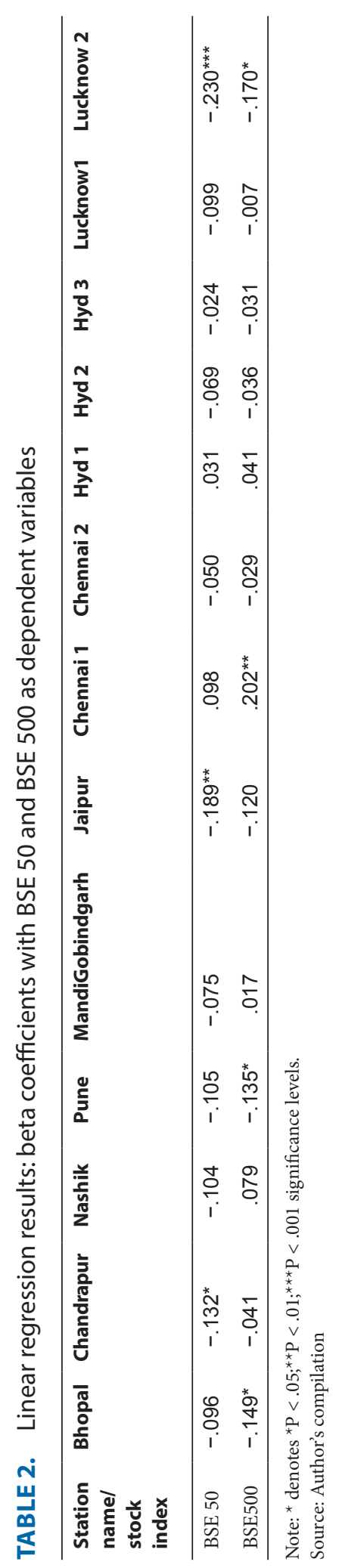




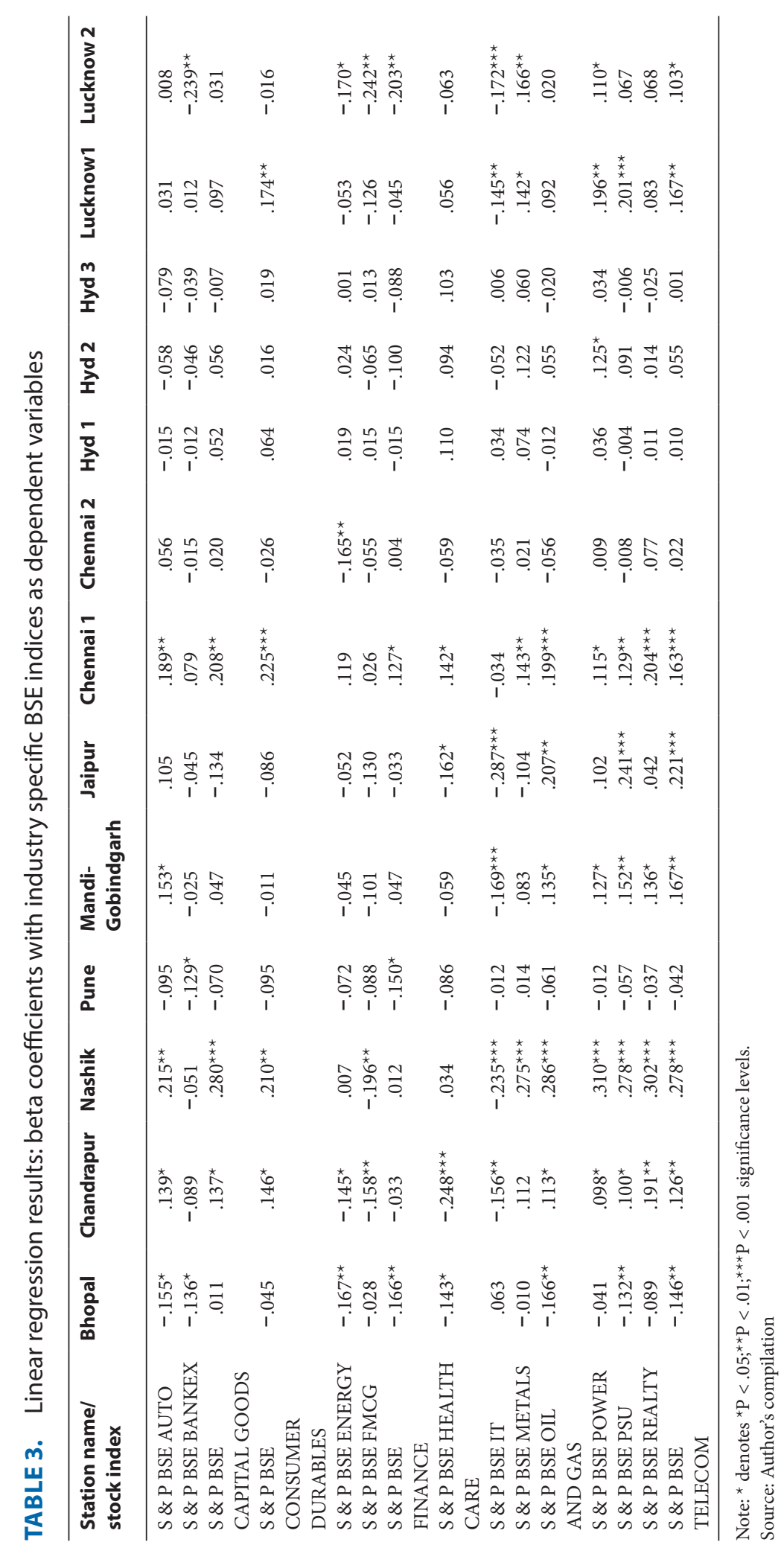


A positive association between $\mathrm{AQI}$ and stock performance, i.e. a worsening air quality leads to positive stock returns, was observed in automobile, capital goods, consumer durables, metals, oil and gas, power, public sector undertakings (PSU), reality, and telecom sectors. One similarity between all these industries is that their production directly impacts the industrial production [21]. A growth of production in these industries results in an increase in pollution, thus worsening air quality, except for telecom industry. Strongest association was observed in automobile, power, PSU, and telecom industry. The power industry is mostly dominated by the public sector which explains the similarity in results for the two industries. Vehicular emissions are one the leading causes for worsening air quality. Auto industry is propelled by increase in consumer demand past decade which explains the positive association between pollution and stock performance for the industry. Telecom industry produced the strongest positive association for AQI and stock performance.

\section{Conclusion}

This study explores the response of Indian stock market to physical environmental stimuli, especially with regard to AQI in short term. We have empirically tested the nature of association between AQI and performance of stock in Indian markets. Our results obtained through regression analysis confirm a negative association between AQI and stock market returns. Statistically significant results were obtained showing that when AQI deteriorates, the stock indices, namely, BSE 50 and BSE 500, are negatively affected. These results confirm similar results obtained by previous studies in China and other parts of the world. India is battling air pollution which is the result of rapid population growth, industrialization, and urbanization. This trend is likely to continue for a few more decades unless drastic measures are initiated in reverse this. Therefore, air pollution not only affects public health but also affects the economy and markets alike. Therefore, it must be considered as possible factor for market behavior in the light of above results.

The study further investigated if similar association exists for industry-wise grouped stocks. The results obtained were very intriguing as a negative association between $\mathrm{AQI}$ and stock performance was observed in banking industry, finance, health care, information technology, FMCG, and energy sectors, while a positive association was observed in automobile, capital goods, consumer durables, metals, oil and gas, power, PSU, reality, and telecom sectors. The nature of production activities engaged by these industries can be a possible reason. While labor-intensive industries displayed a negative relationship, the capital-intensive industries displayed a positive relationship. These results, however, cannot be deemed to connect the investor trading behavior to AQI as trading volumes, volatility, and liquidity in the markets were not studied. The study is exploratory in nature, as very little research is conducted on this aspect in Indian markets. The results are indicative of short-term phenomenon only as the study observed this only for a 1-year period. Interesting findings can be obtained if this phenomenon is studied in long term in Indian markets. Future studies can incorporate other control variables such as economic activity measured by IIP (Industrial index of production, India), location of 
the headquarters of the companies and environmental performance of the companies to explain this phenomenon further.

\section{Disclosure Statement}

No potential conflict of interest was reported by the authors.

\section{Funding}

This work is entirely self-funded.

\section{Acknowledgement}

The authors express their sincere gratitude to the Management, Krupanidhi Group of Institutions for supporting the work through Krupanidhi Research Incubator Centre (K-RIC) program and Accendere: CL Educate Ltd.

\section{References}

1. Selden TM, Song D. Environmental quality and development: is there a Kuznets curve for air pollution emissions? Journal of Environmental Economics and Management. 1994; 27(2), $147-162$.

2. Hirshleifer D, Shumway T. Good day sunshine: stock returns and the weather. The Journal of Finance. 2003; 58(3), 1009-1032.

3. Saunders EM. Stock prices and Wall Street weather. The American Economic Review. 1993; 83(5), 1337-1345.

4. He X, Liu Y. The public environmental awareness and the air pollution effect in Chinese stock market. Journal of Cleaner Production. 2018; 185, 446-454.

5. Amato LH, Amato CH. Environmental policy, rankings and stock values. Business Strategy and the Environment. 2012; 21(5), 317-325.

6. Kong D, Liu S, Dai Y. Environmental policy, company environment protection, and stock market performance: evidence from China. Corporate Social Responsibility and Environmental Management. 2014; 21(2), 100-112.

7. Oberndorfer U, Ziegler A. Environmentally oriented energy policy and stock returns: an empirical analysis release inventory data. Journal of Environmental Economics and Management. 2006; 28(1), 98-113.

8. Li L, Wang Q. The impact of air quality index on stock market. World Economic Research. 2018; $7(2), 48-60$.

9. Li Q, Peng CH. The stock market effect of air pollution: evidence from China. Applied Economics. 2016; 48(36), 3442-3461.

10. Wu Q, Hao Y, Lu J. Air pollution, stock returns, and trading activities in China. Pacific-Basin Finance Journal. 2018; 51, 342-365. 
11. Lu J, Chou RK. Does the weather have impacts on returns and trading activities in order-driven stock markets? Evidence from China. Journal of Empirical Finance. 2012; 19(1), 79-93.

12. Levy T, Yagil J. Air pollution and stock returns in the US. Journal of Economic Psychology. 2011; 32(3), 374-383.

13. Huang X. PM2. 5, Investor sentiment, and stock returns. DEStech transactions on engineering and technology research, (ICAENM). 2017, 1-5.

14. Zhang Y, Jiang Y, Guo Y. The effects of haze pollution on stock performances: evidence from China. Applied Economics. 2017; 49(23), 2226-2237.

15. Haveman RH, Christainsen GB. Environmental regulations and productivity growth. Natural Resources Journal. 1981; 21(3), 489-509.

16. Konar S, Cohen MA. Does the market value environmental performance? Review of Economics and Statistics. 2001; 83(2), 281-289.

17. Murphy CJ. The profitable correlation between environmental and financial performance: a review of the research. Light Green Advisors. 2002, 1-18.

18. Burden of disease attributable to major air pollution. Sources in India. Special report 21. https:// www.healtheffects.org/publication/gbd-air-pollution-india. Date accessed: 21/01/2018.

19. Krzyzanowski M, Cohen A. Update of WHO air quality guidelines. Air Quality, Atmosphere \& Health. 2008; 1(1), 7-13.

20. Klassen RD, McLaughlin CP. The impact of environmental management on firm performance. Management Science. 1996; 42(8), 1199-1214.

21. Repetto R, Austin D. Pure profit: the financial implications of environmental performance. 2000, 1-64.

\section{Annexure}

1. Air Quality Index from the following stations was used from 1 November 2017 to 3 October 2018

\begin{tabular}{lll}
\hline State & City & Station name \\
\hline Madhya & Dewas & Bhopal Chauraha, Dewas - MPPCB \\
Pradesh & Chandrapur & Chandrapur, Chandrapur - MPCB \\
& Nashik & Gangapur Road, Nashik - MPCB \\
& Pune & Karve Road Pune, Pune - MPCB \\
& Mandi Gobindgarh & RIMT University, Mandi Gobindgarh - PPCB \\
& Jaipur & Adarsh Nagar, Jaipur - RSPCB \\
& & Manali, Chennai - CPCB \\
& & Velachery Res. Area, Chennai - CPCB \\
Telangana & Hyderabad & Bollaram Industrial Area, Hyderabad - TSPCB \\
& & ICRISAT Patancheru, Hyderabad - TSPCB \\
& & IDA Pashamylaram, Hyderabad - TSPCB \\
& Lucknow & Central School, Lucknow - CPCB \\
& & Lalbagh, Lucknow - CPCB \\
\hline
\end{tabular}

2. The closing value of the following 17 indices for the period on one year from $1^{\text {st }}$ November 2017 to $31^{\text {st }}$ October 2018, was used in the study 


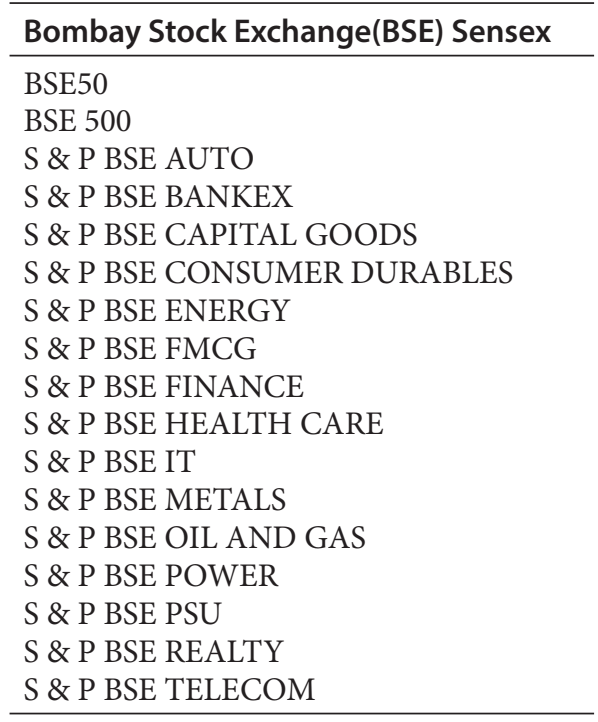

